\title{
Educação para as Relações Étnico-Raciais: possibilidade da educação e um currículo antirracista?
}

\author{
Education for Ethnic-Racial Relations: \\ possibility of an anti-racist education and curriculum?
}

Educación para las relaciones étnico-raciales: ¿posibilidad de una educación y un plan de estudios antirracistas ¿

\author{
Lílian Carine Madureira Vieira da Silva ${ }^{1}$ \\ Rita Cristine Basso Soares Severo ${ }^{2}$
}

\section{RESUMO}

Este artigo trata-se de um recorte do projeto de dissertação do Mestrado Profissional em Educação da Universidade Estadual do Rio Grande do Sul (UERGS). Neste trabalho será discutida a Educação para as Relações Étnico-Raciais como a possibilidade de construção de um currículo e, fundamentalmente, uma escola antirracista. Buscou-se discutir como o currículo está implicado na produção e manutenção de práticas escolares racistas e excludentes. Para compreender os motivos que levam o currículo brasileiro a ser falho para com a população foi importante trazer o conceito de identidade baseado nos Estudos Culturais. Para tanto, foi utilizado como suporte teórico os seguintes autores: CAVALLEIRO (2018), RIBEIRO (2017), GOMES (2005), SILVA (2005), HALL (2003), SANTOMÉ (2001), entre outros. Uma forma de combater o racismo na escola é garantir a efetiva implementação de uma Educação para as Relações Étnico-Raciais, pautada pela igualdade e equidades entre os sujeitos. Desta forma o trabalho tem como objetivo problematizar e questionar o currículo escolar brasileiro, que se mostra voltado aos moldes identitários hegemônicos, logo, lugar de exclusão para com estudantes negros e negras. Contasta-se que para a efetivação da Lei 10.639/03, ou seja, para que a educação antirracista seja uma realidade nas escolas públicass, é essencial a formação continuada de professores e professoras.

PALAVRAS-CHAVE: Estudos Culturais. Currículo. Relações Étnico-Raciais. Educação Antirracista. Lei $10.639 / 03$

Submetido em: 15/01/2021 - Aceito em: 03/03/2021 - Publicado em: 12/07/2021

\footnotetext{
${ }^{1}$ Pedagoga, especialista em Literatura Infantil e Juvenil, mestranda no Mestrado Profissional em Educação da Universidade Estadual do Rio Grande do Sul.

${ }^{2}$ Professora Adjunta do curso de Pedagogia da Universidade Estadual do Rio Grande do Sul. Atua no Mestrado Profissional em Educação da UERGS, na linha de Currículo e formação de professores. Coordena atualmente o projeto de Pesquisa Juventudes em tempos e espaços educativos contemporâneos e Desafios atuais da formação de professores para a educação básica no Brasil - As Licenciaturas na UERGS, com financiamentos UERGS, FAPEGS e CNPQ.
} 


\section{ABSTRACT}

This article is an excerpt from the dissertation project for the Professional Master of Education Degree at the State University of Rio Grande do Sul (UERGS). In this paper, the Education for Ethnic-Racial Relations will be discussed as a possibility for building an anti-racist curriculum and, fundamentally, an anti-racist school. We sought to discuss how the curriculum is involved in the production and maintenance of excluding and raciallybiased scholar practices. In order to understand the reasons that make the Brazilian curriculum fail to reach its population, it was important to bring the concept of identity based on Cultural Studies. For that, the following authors were used as theoretical support: CAVALLEIRO (2018), RIBEIRO (2017), GOMES (2005), SILVA (2005), HALL (2003), SANTOMÉ (2001), among others. One way to fight against racism at school is to ensure the effective implementation of an Education for Ethnic-Racial Relations based on equality and equity among subjects. In this way, the paper aims to problematize and to question the Brazilian school curriculum, which is turned towards hegemonic identity patterns, therefore, a place of exclusion for black students. It is noted that the continuous training of male and female teachers is essential for the effective application of the Law 10.639/03, that is, to make an anti-racist education a reality in public schools.

KEYWORDS: Cultural Studies. Curriculum. Ethnic-Racial Relations. Anti-racist Education. Law 10.639/03.

\section{RESUMEN}

Este artículo es un extracto del proyecto de tesis de maestría profesional en Educación en la Universidade Estadual do Rio Grande do Sul (UERGS). Este trabajo discutirá la Educación para las Relaciones ÉtnicoRaciales como una posibilidad de construir un plan de estudios y, fundamentalmente, una escuela antirracista. Buscamos discutir cómo el plan de estudios es involucrado en la producción y mantenimiento de prácticas escolares racistas y excluyentes. Para comprender las razones que hacen que el currículo brasileño no atienda a la población, fue Importante traer el concepto de identidad basado en Estudios Culturales. Para eso se utilizó como soporte teórico los siguientes autores: CAVALLEIRO (2018), RIBEIRO (2017), GOMES (2005), SILVA (2005), HALL (2003), SANTOMÉ (1995), entre otros. Una forma de combatir el racismo en la escuela es garantizar la implementación de una educación enfocada en las Relaciones Étnico-Raciales, basado en la igualdad y equidad entre sujetos. De esta forma el trabajo tiene como objetivo problematizar y cuestionar el plan de estudios escolar brasileño, que se presenta a moldes de identidad hegemónica, logo, lugar de exclusión para estudiantes negros y negros. Se dice que para la aplicación de la Ley 10.639 / 03, es decir, que la educación antirracista sea una realidad en las escuelas públicas, la formación continua de profesores y profesores.

PALABRAS CLAVE: Estudios culturales. Plan de estudios. Relaciones Étnico-Raciales. Educación antirracista. Ley $10.639 / 03$.

\section{INTRODUÇÃO}

Compreender a importância da implementação da Lei 10.639/03 - que torna obrigatório o ensino de história e cultura africana e afro-brasileira em todo o currículo escolar, em instituições públicas e privadas - seu cumprimento e a aplicação da Educação para as 


\section{Revista Docência e Cibercultura}

Relações Étnico-Raciais $\left(\mathrm{ERER}^{3}\right.$ ) é passo fundamental para que uma política efetivamente antirracista realmente torne-se uma realidade em nosso país. Para que a urgência da educação antirracista seja percebida, é essencial a tomada de consciência de professores e professoras da educação básica: de seu lugar de fala e sua função, na sociedade, como formadores de pensamento crítico a partir do momento em que lecionam para crianças.

Entendemos que existe um local específico de fala que é ocupado pelos docentes, pois, independentemente da etnia deste profissional, é bem provável que, na educação básica e pública brasileira, a sala de aula seja multiétnica e o professor tenha que lidar com conflitos raciais, e se apropriar dos conhecimentos da ERER. Não só pelo fato de ter alunos brancos, negros, pardos etc., mas além disso, por ser um imperativo legal. Sendo assim, mesmo quem leciona em uma escola particular, com mensalidade que pode custar alguns milhares de reais, e tem apenas alunos não-negros em sala, deve colocar a Lei 10.639/03 em prática. A ERER é para todos, não importa a etnia.

É a partir deste entedimento que passamos a questionar o currículo escolar brasileiro, entendendo ele como local de exclusão identitária para com os grupos considerados minorias, socialmente falando. A partir de nossos estudos e observações do dia a dia da educação pública, seja nas escolas, seja nas universidades, estendendo-se para a sociedade brasileira, fomos capazes de perceber esse lugar, como professoras, de condutoras para a formação do pensamento crítico. Compreendemos que tanto a Lei 10.639/03 quanto a ERER surgem no sentido de reparar e problematizar os erros históricos brasileiros e de sua sociedade, assim como o desastre socieconômico a que uma sociedade racista se joga.

Portanto, buscamos nos juntar, enquanto professoras de escolas e universidades públicas, na defesa da equidade racial. Sabendo que individualmente não somos iguais, torna-se necessário buscar a equidade para que se possam criar oportunidades justas de acesso fundamental aos direitos básicos. Então, quando falamos sobre equidade racial, partimos do entendimento de que não existe uma igualdade real de condições e oportunidades em nosso

\footnotetext{
${ }^{3}$ Para próximas menções à Educação para as Relações Étnico-Racias será utilizada a sigla ERER.
} 
país. Foi assim que surgiu uma filha ingrata da Democracia Racial ${ }^{4}$ : a meritocracia, que busca silenciar as desigualdades raciais brasileiras com o discurso do esforço pessoal para que os objetivos de uma pessoa sejam alcançados. Esse é um discurso cruel, insensível e excludente. Afinal, não leva em consideração os quase quatro séculos de escravização de povos africanos em território brasileiro e toda a exclusão social e econômica sofrida pelos negros e negras.

Por isso são tão importantes as medidas equitárias paliativas como a instauração das cotas raciais universitárias, entre outras. A igualdade só se consolidará quando as medidas de equidade forem tomadas. O racismo está enraizado estrutural e institucionalmente no Brasil e a inclusão de negros e negras nas instâncias privadas e públicas é urgente.

Tendo em vista nosso posicionamento na área da educação pública, e na sociedade, e a partir de nossas observações e vivências no chão da sala de aula, surgiu o questionamento: estudantes negros e negras sentem-se representados (as) no currículo escolar e no próprio espaço de ensino-aprendizagem? Para responder a esta questão delineamos como objetivo problematizar e questionar o currículo escolar brasileiro, que se mostra voltado aos moldes identitários hegemônicos. Traremos reflexões sobre nosso currículo e sobre a ERER.

\title{
UMA REFLEXÃO SOBRE CURRÍCULO E ESPAÇOS E TEMPO ESCOLARES
}

\begin{abstract}
Quando criança, fui ensinada que a população negra havia sido escrava e ponto, como se não tivesse existido uma vida anterior nas regiões de onde essas pessoas foram tiradas a força. Disseram-me que a população negra era passiva e que "aceitou" a escravidão sem resistência. Também contaram que a princesa Isabel foi sua grande redentora. [ . . . $\mathrm{O}$ que não me contaram é que o Quilombo dos Palmares, na serra da Barriga, em Alagoas, perdurou por mais de um século, e que se organizaram vários levantes como forma de resistência à escravidão, como a Revolta dos Malês e a Revolta da Chibata. Com o tempo, compreendi que a população negra havia sido escravizada, e não era escrava - palavra que denota que essa seria uma condição natural, ocultando que esse grupo foi colocado ali pela ação de outrem. (RIBEIRO, 2019, p. 5)
\end{abstract}

\footnotetext{
${ }^{4}$ Diz respeito a uma narrativa que defende que o Brasil é um país de convivência harmoniosa entre todas os povos que compõem a nação e no qual não existe racismo, devido à circulação da cultura diversa na sociedade, à relação entre brancos e negros mas, desde que esses últimos ocupem lugares subalternos em detrimento aos primeiros.
} 
Para discutir como e por quem as histórias são contadas no currículo escolar, apresentamos o excerto do livro "Pequeno manual antirracista" (2019) da filósofa e pesquisadora Djamila Ribeiro, uma das vozes do feminismo negro brasileiro. A partir dos estudos de Silva (2002), (2006), Santomé (2001 e, em especial, de Michael Apple (2002), em seu texto, “A política do conhecimento oficial: faz sentido a ideia de um currículo oficial?” podemos refletir que a educação está intimamente ligada a política cultural, que o currículo não é construído de forma neutra e desinteressada, constituindo-se em um campo de luta pela busca de significados. Para o autor o currículo é "sempre parte de uma tradição seletiva, resultado da seleção de alguém, da visão de algum grupo acerca do que seja conhecimento legítimo." (APPLE, 2002, p. 59).

O que conta como conhecimento? Quem tem autoridade para transmiti-lo? O momento contemporâneo brasileiro nos leva a resgatar os questionamentos feitos por Apple em 2002, em outro tempo e espaço, mas que nos auxiliam a refletir acerca deste momento no qual as vozes liberais conservadoras vêm asseverando práticas preconceituosas e racistas fundamentalmente nos espaços institucionalizados, dentre eles, a escola. Nessa perspectiva questionamos: por que os currículos escolares silenciam e até mesmo negam a participação de negros e negras na história do Brasil? Será que os (as) estudantes negros e negras se sentem representados (as) no currículo escolar? Eles (as) veem ali sua ancestralidade e sua história representadas de forma positiva? Como é construída a identidade dessas crianças e jovens na experiência escolar?

Para pensar na direção destes questionamentos, Silva (1996, p. 23) considera o currículo como:

\footnotetext{
Um dos locais privilegiados onde se entrecruzam saber e poder, representação e domínio, discurso e regulação. É também no currículo que se condensam relações de poder que são cruciais para o processo de formação de subjetividades sociais. Em suma, currículo, poder e identidades sociais estão mutuamente implicados. O currículo corporifica relações sociais.
}

Na mesma direção, Santomé (2001) lembra que alguns grupos são, também, marginalizados e silenciados; logo, não dispõem de estruturas de poder, sendo assim, acabam por ser anulados em suas possibilidades de reação. Há avanço, mas ainda há muito a se fazer no currículo 
escolar brasileiro. Djamila Ribeiro (2019), na sequência do livro destacado no início desta seção, descreve, de forma contundente, o modo como foi se constituindo criança, jovem e mulher negra nas suas relações com a escola, primeiro lugar que a autora destaca em que sentiu as marcas do racismo além de sua "inadequação" aos modelos de sujeitos "desejáveis" para a sociedade brasileira.

Santomé (2001), analisando um contexto social diferente do brasileiro, mas produtivo para pensarmos, ressalta que o currículo predefine um modelo de sujeito a ser constituído:

\footnotetext{
Muitas propostas de escolarização mantêm ainda uma forte estrutura fordista, no sentido de que seu modo de funcionamento se assemelha ao de cadeia de montagem de uma fábrica.[...] O que tem menos importância nessa situação é o sentido, a utilidade e o domínio real do que devem aprender. (SANTOMÉ, 2001, p. 160).
}

Tendo em mente que o currículo é uma invenção social, criado por grupos hegemônicos, ele torna-se um reflexo daquela cultura e modos de ser e pensar sobre o mundo. Nos amparamos em Alfredo Veiga-Neto (2002) ao afirmar que o currículo corresponde à cultura na qual ele foi organizado; ali percebemos a prioridade dada a determinados conteúdos curriculares em lugar de outros, "isto é, podemos inferir quais foram os critérios de escolha que guiaram os professores, administradores, curriculistas etc. que montaram aquele currículo." (VEIGANETO, 2002, p. 44).

Entretanto, sabemos que a sala de aula é lugar de pluralidades e que cada estudante carrega em si e vive sua própria cultura além dos muros da escola. Aqui surge um primeiro e dos mais relevantes pontos de exclusão que o currículo traz: o da cultura, como tão bem mencionou Djamila Ribeiro (2019), contando sua passagem pela escola e como a história de sua ancestralidade foi contada de forma parcial e distorcida.

Ao narrar-se como inadequada a autora nos remete a pensar na constituição identitária como construída na e por meio da linguagem. Para esta afirmação, tomamos como base Stuart Hall (2014): 
É precisamente porque as identidades são construídas dentro e não fora do discurso que nós precisamos compreendê-las como produzidas em locais históricos e institucionais específicos, no interior de formações e práticas discursivas específicas, por estratégias e iniciativas específicas. (p. 109).

Isso significa que as identidades são demarcadas por sistemas simbólicos. Outro marcador da identidade é a diferença, que também ocorre por sistemas simbólicos de representação e de exclusão social, logo, a identidade depende da diferença para existir e ser reivindicada e viceversa. (Woodward, 2014).

E quando a identidade é demarcada pelo racismo? Há cinco séculos, as garras do colonialismo foram cravadas no continente africano. Primeiramente com argumentos religiosos e depois com base na eugenia que, baseada em uma ciência inventada, pois não havia, de fato, fundamentação científica para justificá-la, buscava "melhorar" a raça humana e justificava a inferioridade das etnias não brancas. Desde então, os africanos e seus descendentes vêm sendo submetidos a todo tipo de rótulos negativos de identidade. (Munanga, 2019).

Esses povos passaram a ter uma identidade atribuida pelo outro, pelo branco. Consideramos relevante para essa discussão, mencionar:

[...] o fato de (os negros) terem sido na história vítimas das piores tentativas de desumanização e de terem sido suas culturas não apenas objeto de políticas sistemáticas de destruição, mas, mais do que isso, de ter sido simplesmente negada a existência dessas culturas. Lembremos que, nos primórdios da colonização, a África negra foi considerada como um deserto cultural, e seus habitantes como o elo entre o Homem e o macaco. (MUNANGA, 2019, n.p ${ }^{5}$ )

Essa classificação, produzida por uma sociedade dominante, acaba por hierarquizar as identidades e "deter o privilégio de classificar significa também deter o privilégio de atribuir diferentes valores aos grupos assim classificados." (SILVA, 2014, p. 82). Sendo assim, pode-

\footnotetext{
${ }^{5}$ Livro no formato kindle, não paginado.
} 
se dizer que a identidade negra é sufocada e suprimida pelo racismo e pelos estereótipos que o preconceito atribui a essas pessoas. Quando se hierarquiza uma identidade em comparação a outra, fixa-se essa identidade escolhida como norma e essa norma, diz Silva (2014), é uma das formas como o poder se manifesta no campo da identidade e da diferença.

Normalizar uma identidade torna-se um jogo perigoso para quem é identificado como o outro, ou seja, qualquer minoria. É um jogo perigoso, pois é a identidade que foi normalizada que recebe as características positivas, logo, as outras são caracterizadas de forma negativa. A identidade normalizada não é mais um tipo de identidade, mas o padrão esperado de como ser e se portar.

Contudo, essa normalização passou a ser questionada cada vez mais, com o fortalecimento dos movimentos sociais, por exemplo. As identidades passaram a ser contestadas. Vale lembrar que "É apenas por meio de atos de fala que instituimos a identidade e a diferença como tais." (SILVA, 2014, p. 77). O empoderamento das minorias, como os de sujeitos que chegam às universidades, seu poder de fala adquirido através de sua própria produção intelectual, colocaram em cheque a identidade branca dominante, como ressalta Hall (2003):

Dentro da cultura, a marginalidade, embora permaneca periférica em relação ao mainstream, nunca foi um espaço tão produtivo quanto é agora, e isso não é simplesmente uma abertura, dentro dos espaços dominantes, a ocupação dos de fora. É também o resultado de políticas culturais da diferença, de lutas em torno da diferença, da produção de novas identidades e do aparecimento de novos sujeitos no cenário político e cultural. Isso vale não somente para a raça, mas também para outras etnicidades marginalizadas (p. 338).

Essa contestação é essencial e deve ser sempre trazida à tona em torno das relações sociais vigentes. Afinal, ao conquistar o poder sobre a própria narrativa, os grupos minoritários reivindicam contar sua própria história. A reinvidicação é histórica, as conquistas que presenciamos hoje são fruto de longa luta. 
Voltando 151 anos na história, deparamo-nos com uma lei de 1837, nela consta que escravos e pretos africanos estavam proibidos de frenquentar a escola pública, mesmo que libertos ou livres. Evidentemente, essas pessoas não cruzaram os braços: "Os negros criaram a imprensa negra, escolas, clubes recreativos ou associações, entidades religiosas ou beneficentes, grupos culturais e teatros amadores." (CRUZ, 2005, p. 22). Embora sempre tenha havido luta, pouco sabemos dela; a respeito da história da educação da população negra, Cruz (2005) ressalta:

A problemática da carência de abordagens históricas sobre as trajetórias educacionais dos negros no Brasil revela que não são os povos que não têm história, mas há os povos cujas fontes históricas, ao invés de serem conservadas, foram destruídas nos processos de dominação. (p. 23).

Em 2003 entrou em vigor a Lei 10.639 que "altera a Lei no 9.394/96 nos seus artigos 26 e 79, e torna obrigatória a inclusão no currículo oficial de ensino da temática 'História e Cultura Afro-brasileira" (DIAS, 2005, p. 58).

A íntegra da Lei diz:

"Art. 26-A. Nos estabelecimentos de ensino fundamental e médio, oficiais e particulares, torna-se obrigatório o ensino sobre História e Cultura Afro-Brasileira.

$\S 1$ ㅇ O conteúdo programático a que se refere o caput deste artigo incluirá o estudo da História da África e dos Africanos, a luta dos negros no Brasil, a cultura negra brasileira e o negro na formação da sociedade nacional, resgatando a contribuição do povo negro nas áreas social, econômica e política pertinentes à História do Brasil.

§ 2o Os conteúdos referentes à História e Cultura Afro-Brasileira serão ministrados no âmbito de todo o currículo escolar, em especial nas áreas de Educação Artística e de Literatura e História Brasileiras.

Art. 79-B. O calendário escolar incluirá o dia 20 de novembro como 'Dia Nacional da Consciência Negra'." 
Para seguir com a discussão torna-se essencial o debate sobre a prática do racismo no cotidiano das escolas, prática esta que deixa marcas em estudantes negros e negras, que faz com que crianças e jovens não sejam acolhidos por esta instituição. $\mathrm{O}$ racismo vivenciado por estudantes negros e negras fala que o lugar deles não é na escola. Como veremos na próxima seção deste trabalho.

\section{ENTRE AS PAREDES DA ESCOLA: AS MARCAS DE PRÁTICAS ESCOLARES E DE UM CURRÍCULO RACISTA}

Entendemos que o preconceito racial se manifesta na escola de diversas formas, nas relações mais sutis (ou não) tais como: pelas expressões racistas entre estudantes ou entre professores (as) e estudantes ou ainda pela omissão e silêncio em práticas excludentes. Descrevemos a seguir o silêncio e o ocultamento da imagem do (a) negro (a) nos espaços da escola e até mesmo super-representação da imagem do branco.

Quando entramos em uma Escola da Educação Básica nos deparamos com suas paredes decoradas, nelas estão "pendurados" os sujeitos "válidos", “dignos de serem mostrados". Geralmente as decorações e quadros mostram crianças brancas recortadas em EVA, quadros de santos protetores, brancos, de religião católica, princesas e personagens de animação que denotam a branquitude e a cultura eurocêntrica. Ao adentrar as salas de aula observa-se, geralmente, entre brinquedos espalhados por lá, que a grande maioria são bonecas brancas e brinquedos que representam modos de vida europeus e estadunidense.

Ao folhearmos os livros didáticos e literários disponíveis neste espaço, visualizamos histórias que destacam os modos e experiências de povos europeus, quando chegamos mais perto dos livros percebemos que, em sua grande maioria, retratam personagens protagonistas brancos. Poucos são os livros com protagonismo negro e, geralmente, quando isso acontece a narrativa está ligada a assuntos como o racismo, ou o preconceito contra o cabelo crespo. Dificilmente as histórias com esses personagens não estarão atreladas à temática étnica, dificilmente será 
vislumbrado um personagem negro em uma aventura espacial ou sendo o mais belo de toda a região.

Descrevemos, no excerto acima, experiências percebidas em nossas andanças enquanto professoras e trazemos Cristiane Fammer Rocha (2000) para nos auxiliar a pensar sobre as práticas escolares marcadas pelas relações de poder e para refletir sobre práticas racistas nos espaços da escola. Considera ela:

São as práticas escolares - ai incluídos os espaços técnica e pedagogicamente constituídos - que contribuem fortemente para fazer de nós aquilo que nós somos. Pois, dentro dos espaços escolares - e a partir deles e suas diversas relações e interrelações é que se dá o exercício pedagógico. (ROCHA, 2000, p. 10)

A autora afirma que, além dos aspectos arquitetônicos, a sala de aula, e, por extensão, os espaços da escola, implicam uma relação de comunicação entre os sujeitos. Há o lugar de quem fala e o lugar de quem escuta, certamente esta é uma comunicação hierárquica. Sabemos também que é uma relação que não está pautada simplesmente no saber, que não se trata apenas de quem sabe mais, mas se estabelece uma relação de poder a qual dita quem pode ou não ser representado nos espaços escolares.

Logo, surge o questionamento sobre a criança que não se reconhece na decoração da escola, cujo passado ancestral é retratado apenas com a escravização dos africanos e quando as falas sobre África são um discurso cheio de estereótipo ao invés de problematizado, além disso a história de África apresentada em salas de aula brasileiras é retratada apenas a partir do momento da colonização europeia daquele continente. Essa criança é acolhida como parte integrante daquele ambiente?

Supõe-se que a escola é um lugar onde pousam doces memórias: alguma professora querida, brincadeiras com os colegas, aquele almoço muito bom ou muito ruim do refeitório, uma "cola" flagrada durante a prova, um namorico. No entanto, a escola pode ser um lugar de exclusão e traumas também. 
Deparamo-nos, então, com um dos problemas do currículo brasileiro: a falta de representação das minorias de um modo geral, e da população afro-brasileira especificamente a ser tratada neste artigo. Sendo assim o currículo, eurocentrado, xenófobo e heteronormativo torna-se um lugar de exclusão: cultural, de identidade e de representação. Ao ignorar que a sala de aula é plural, o currículo trata as "minorias" reduzindo-as ao calendário das datas comemorativas; como algo exótico e marcadas por estereótipos. Tornando a diversidade algo negativo na sala de aula.

Sendo assim, é nescessário repensar o currículo brasileiro para que ele abrace a cultura e a história afro-brasileira e africana. O nosso país é o maior em população negra fora da África e o segundo no mundo, apenas na Nigéria vivem mais negros. Chega a ser ilógico sabermos tão pouco a respeito dessas temáticas.

Muito mais do que um conteúdo curricular, a inserção da discussão sobre a África e a questão do negro no Brasil nas escolas da educação básica têm como objetivo promover o debate, fazer circular a informação, possibilitar análises políticas, construir posturas éticas e mudar o nosso olhar sobre a diversidade. (GOMES, 2008, p. 81).

Longe do discurso da Democracia Racial, mas no entendimento de que o diverso amplia nossa visão de mundo e nos torna mais compreensíveis em relação ao outro, expandindo a nossa consicência ética e estética também.

\section{A ERER NO CURRÍCULO E NAS SALAS DE AULA}

A escola é lugar de convivência, aprendizagens, socialização e de desafios e inovações. A educação escolar em nosso país, assim como no mundo todo, passou por mudanças através da história. Houve tempos em que as turmas eram unificadas e as crianças não eram separadas pela idade, tempos esses de educação voltada ao ensino religioso, de educação exclusiva para meninos, de educação exclusiva para ricos e, no Brasil, de educação exclusiva para brancos. 
Em 1824 foi declarado, na Constituição, que todos os cidadãos tinham direito à instrução primária gratuita. No entanto, eram impedidos de cidadania os indígenas e os negros escravizados, além de trabalhadores braçais; era de comum senso que essas pessoas não precisavam ser instruídas. (Brasil, 2000). Em 1837, como visto anteriormente, entrou em vigor a lei que proibia o acesso de negros às escolas. Daremos um salto de dois séculos para então nos depararmos com a Lei 10.639, promulgada em 2003 (isso aconteceu apenas no século XXI).

Esta importante e fundamental Lei é fruto da luta do Movimento Negro, que busca por justiça social e surge como uma proposta de ruptura ao currículo escolar vigente. Este movimento executa importantíssimo papel em nossa sociedade, como afirma Gomes (2017):

[...] o Movimento Negro, enquanto forma de organização política e de pressão social - não sem conflitos e contradições - tem se constituído como um dos principais mediadores entre a comunidade negra, o Estado, a sociedade, a escola básica e a universidade. Ele organiza e sistematiza saberes específicos construídos pela população negra ao longo da sua experiência social, cultural, histórica, política e coletiva. (p. 42).

A ERER, de acordo com as Diretrizes Curriculares Nacionais para a Educação das Relações Étnico-Raciais e para o Ensino de História e Cultura Afro-Brasileira e Africana (2004), diz respeito

[...] ao reconhecimento e valorização da história e cultura dos afro-brasileiros, à diversidade da nação brasileira, ao igual direito à educação de qualidade, isto é, não apenas direito ao estudo, mas também à formação para a cidadania responsável pela construção de uma sociedade justa e democrática. (BRASIL, 2004, p. 10).

Além disso, ela "impõe aprendizagens entre brancos e negros, trocas de conhecimentos, quebra de desconfianças, projeto conjunto para construção de uma sociedade justa, igual, equânime.” (BRASIL, 2004, p. 14). Ou seja, quando se fala sobre obrigatoriedade do ensino de história e cultura afro-brasileira não está implícito, de forma alguma, que está sendo exigido exclusividade de ensino de temáticas afro-brasileiras nas escolas, mas que estas também precisam ser vistas em sala de aula. 
Assim se desmancha preconceito e racismo, assim se recupera a autoestima de crianças negras e se estimula o mútuo respeito. Já que:

Em uma sociedade multirracial e pluricultural, como é o caso do Brasil, não podemos mais continuar pensando a cidadania e a democracia sem considerar a diversidade e o tratamento desigual historicamente imposto aos diferentes grupos sociais e étnico-raciais. (GOMES, 2008, p. 70).

Entretanto, a ERER na sala de aula, muitas vezes, está atrelada apenas ao "Novembro Negro", única época do ano em que as escolas, geralmente, abordam projetos sobre temáticas africanas, e que acaba sendo aplicada de forma equivocada quando reproduz o racismo estrutural em forma de "homenagem", como fazer o black face, ${ }^{6}$ pintando o rosto dos alunos de preto, quando se fala de "consciência humana no lugar de consciência negra"; ou de forma superficial quando fica no âmbito da contribuição com atividades que não trazem conscientização ou reflexão e que não se encaminham para uma atitude antirracista porque não são atividades antirracistas.

A escola, como mencionamos anteriormente, é também o lugar onde muitas vezes a criança negra vivencia o racismo pela primeira vez. Ele aparece através de apelidos pejorativos, no livro didático, e até no silêncio da professora diante do preconceito que o estudante negro sofre. Cavalleiro (2018) afirma que esse silêncio "[...] facilita novas ocorrências, reforçando inadvertidamente a legitimidade de procedimentos preconceituosos e discriminatórios no espaço escolar e, com base neste, para outros âmbitos sociais.” ( p. 10).

Um dos pontos mais importantes da Lei 10.639/03 é exatamente valorizar a cultura e a história do povo afro-brasileiro dentro da escola. Sobre essas práticas pedagógicas, Gomes (2005) ressalta:

\footnotetext{
${ }^{6} \mathrm{O}$ black face era uma prática comum nos Estados Unidos segregados, e consistia no costume de artistas brancos pintarem seus rostos de preto para interpretarem, de forma pejorativa, personagens negros. Geralmente vagabundos e alcólotras, além de miséraveis.
} 
É preciso que as práticas pedagógicas sejam orientadas por princípios éticos que norteiem as relações estabelecidas entre professores, pais e alunos no interior das escolas brasileiras. E é necessário inserir a discussão sobre o tratamento que a escola tem dado às relações raciais no interior desse debate. (GOMES, 2005, p. 150).

Muitas vezes a escola demonstra que não compreende a demanda da própria comunidade em que está inserida. Gomes (2005) relata que "é preciso que a escola se conscientize cada vez mais de que ela existe para atender à sociedade na qual está inserida e não aos órgãos governamentais ou aos desejos dos educadores" (p. 147).

Sendo a escola um dos primeiros lugares em que a criança começa a socializar fora do ambiente familiar, esta torna-se cenário importante na luta antirracista pois, como afirma Cavelleiro (2018), a escola que não se posiciona contra o racismo acaba por legitimá-lo. A partir do momento em que a escola não se posiciona, torna-se um local de exclusão para a criança negra e onde a criança branca passa a ter a equivocada ideia de superioridade racial. Por isso a urgência do cumprimento da Lei 10.639/03.

Consta nas Diretrizes Curriculares Nacionais para a Educação das Relações Étnico-Raciais e para o Ensino de História e Cultura Afro-Brasileira e Africana que cabe ao Estado promover e incentivar as políticas de reparação por meio da educação, já que

Sem a intervenção do Estado, os postos à margem, entre eles os afro-brasileiros, dificilmente, e as estatísticas o mostram sem deixar dúvidas, romperão o sistema meritocrático que agrava desigualdades e gera injustiça, ao reger-se por critérios de exclusão, fundados em preconceitos e manutenção de privilégios para os sempre privilegiados. (BRASIL, 2004, p. 11).

Fica explícito que o reflexo da exclusão da população negra brasileira na história da educação escolar ainda reluz com força em nossa sociedade, por isso o papel do Estado como promotor e incentivador da igualdade racial é fundamental. Para que isso se torne uma realidade em nosso país, cabe também à sociedade cobrar do Estado por políticas de formação continuada de professores e por acesso a materiais de qualidade para que a educação antirracista seja uma realidade nas escolas brasileiras. 


\section{A título de finalizar o artigo... Por uma escola antirracista}

Se refletir, tematizar e problematizar sobre o mundo não é condição suficiente para transformá-lo, é sempre condição necessária. (VEIGA-NETO, 2002, p. 50).

Ao longo da leitura foi constatado o quanto o currículo brasileiro pode ser considerado defasado diante da realidade multiétnica da sala de aula. É importante ressaltar que notamos dois lados de uma mesma moeda:

1) as escolas encontram dificuldade em implementar a Lei 10.639/03 devido a diversos fatores, tais como: omissão do Estado, que precisa promover e tornar acessível a formação continuada de professores e professoras, já que, tendo em mente que a Lei é de 2003, muitos deles não tiveram acesso à ERER em suas graduações; além, óbvio da falta de interesse da escola e de seus funcionários em adotar a educação antirracista. Essa falta de comprometimento contribui para a perpetuação e naturalização do racismo.

Essas escolas demonstram que encontram dificuldades em lidar com a divresidade, tornando o "outro" exótico, pitoresco, o diferente e fora do padrão.

2) O outro lado da moeda é o exato oposto. Ocorre quando a escola compreende ser um espaço multiétnico e plural em diversos sentidos e percebe o quanto é essencial adotar a postura antirracista diante da comunidade em que está inserida. Juntamente a isso não há como uma escola ser antirracista se os professores e professoras não buscarem por isso, ou melhor, não forem atendidos quanto a esta demanda específica em sua formação. É essencial que a escola e os professores sejam engajados na causa.

É possível afirmar que a formação continuada de professores é uma das peças mais importantes, de fato, a pedra fundamental da educação antirracista, que precisa desses profissionais para acontecer. Porém, queremos ressaltar que, apesar da responsabilidade de estar na sala de aula aplicando o conteúdo antirracista, os professores não são heróis 
solitários, esses profissionais precisam de uma rede de apoio: das secretarias, das famílias dos estudantes, do Estado.

Fica evidente que escola é um local apropriado para a ação positiva que venha a desconstruir estereotipias e racismo, afinal, a educação é um direito de todos e todas. Por abranger todo o currículo escolar a Lei 10.639/03 abre espaço para grandes atividades multi e interdisciplinares, envolvendo professores de diversas disciplinas, inclusive diversas séries. Já que, a interdisciplinaridade e a ERER são estímulos para a abertura de diálogos, para olhar e compreender o "outro", como também à autocrítica. Além disso, traz dinamicidade ao currículo escolar.

Esta Lei pode gerar uma movimentação de integração e partilha entre estudantes e colegas de trabalho de toda a escola. Acreditamos que a coletividade e o respeito mútuo são chave para a educação cidadã e inclusiva.

\section{REFERÊNCIAS}

APPLE, Michael W. A política do conhecimento oficial: faz sentido a ideia de um currículo nacional? In: MOREIRA, Antônio Flávio Barbosa; SILVA, Tomaz Tadeu da (Orgs).

Currículo, cultura e sociedade. 7 ed. São Paulo: Cortes, 2002.

BRASIL. História e Cultura Afro-Brasileira. Lei Federal nº10.639/2003.

BRASIL. Lei n⿳1/1837 e o Decreto n⿳15, de 1839, sobre Instrução Primária no Rio de Janeiro.

BRASIL. Parecer no 11/2000, de 10 de maio de 2000. Brasília: CNECEB/MEC.

BRASIL. Diretrizes Curriculares Nacionais para a Educação das Relações ÉtnicoRaciais e para o Ensino de História e Cultura Afro-Brasileira e Africana. Conselho Nacional de Educação, 10 de março de 2004.

CAVALLEIRO, Eliane dos Santos. Do silêncio do lar ao silêncio escolar - racismo, preconceito e discriminação na educação infantil. 6 ed. São Paulo: Contexto, 2018. 
CRUZ, Mariléia dos Santos. Uma abordagem sobre a história da educação dos negros. In: ROMÃO, Jeruse (Org.). História da educação do negro e outras histórias. Secretaria de Educação Continuada, Alfabetização e Diversidade. Brasília: Ministério da Educação, Secretaria de Educação Continuada, Alfabetização e Diversidade. 2005.

DIAS, Lucimar Rosa. Quantos passos já foram dados? A questão de raça nas leis educacionais - da LDB de 1961 à Lei 10.639 de 2003. In: ROMÃO, Jeruse (Org.). História da educação do negro e outras histórias. Secretaria de Educação Continuada, Alfabetização e Diversidade. Brasília: Ministério da Educação, Secretaria de Educação Continuada, Alfabetização e Diversidade, 2005.

GOMES, Nilma Lino. Educação e relações raciais: refletindo sobre algumas estratégias de atuação. In: MUNANGA, Kabengele. (Org). Superando o racismo na escola. Brasília: SECAD, 2005.

GOMES, Nilma Lino. A questão racial na escola: desafios colocados pela implementação da Lei 10.639/03. In: MOREIRA, Antônio Flávio; CANDAU, Vera Maria Candau (Orgs.). Multiculturalismo: diferenças culturais e práticas pedagógicas. 2. ed. Petrópolis: Vozes, 2008.

GOMES, Nilma Lino. (org.) Práticas Pedagógicas de trabalho com as relações étnicoraciais na escola na perspectiva da Lei $\mathbf{n}^{\mathbf{0}} \mathbf{1 0 . 6 3 9 / 0 3}$. Brasília: MEC; UNESCO, 2012.

GOMES, Nilma Lino. O movimento negro educador - saberes construídos nas lutas por emancipação. Petrópolis: Vozes, 2017.

HALL, Stuart. Quem precisa de identidade? In: SILVA. Tomaz Tadeu (Org.). Identidade e diferença - a perspectiva dos Estudos Culturais. 15 ed. Petrópoles: Vozes, 2014.

HALL, Stuart. Da diáspora - identidade e mediações culturais. Belo Horizonte: Editora UFMG, 2003.

MUNANGA, Kabengele. Negritude - usos e sentidos. 4 ed. Belo Horizonte: Autêntica, 2019. Edição do Kindle. Não paginado.

RIBEIRO, Djamila. O que é: lugar de fala? Belo Horizonte (MG): Letramento: Justificando, 2017

RIBEIRO, Djamila. Pequeno manual antirracista. São Paulo: Companhia das letras, 2019. Edição do Kindle. Não paginado.

ROCHA, Rosa Margarida de Carvalho.; TRINDADE, Azoilda Loretto da. Ensino Fundamental. In: Orientações e ações para a educação das relações étnico-raciais. 2 ed. Brasília: SECAD, 2006.

ROCHA, Cristiane Maria Fammer. Desconstruções edificantes: uma análise da ordenação do espaço como elemento do currículo. Porto Alegre: UFRGS, 2000. Dissertação. 
(Mestrado em Educação). Programa de Pós-graduação em Educação, Faculdade de Educação, Universidade Federal do Rio Grande do Sul.

SANTOMÉ, Jurjo Torres. As culturas negadas e silenciadas no currículo. In: SILVA, Tomaz Tadeu. Alienígenas na sala de aula - uma introdução aos estudos culturais em educação. 3 ed. Petrópolis: Vozes, 2001.

SILVA, Ana Célia da, A desconstrução da discriminação no livro didático. In: MUNANGA, Kabengele. (Org). Superando o racismo na escola. Brasília: SECAD, 2005.

SILVA, Tomaz Tadeu da. Documentos de identidade: Uma introdução às teorias do currículo, - 2 ed, $9^{\circ}$ reimp. - Belo Horizonte: Autêntica, 2005.

SILVA, Tomaz Tadeu da. (org) Identidade e diferença: a perspectiva dos estudos culturais. Petrópolis, Rio de Janeiro: Vozes, 2000.

SILVA, Tomaz Tadeu da. Identidades terminais: as transformações na política da pedagogia e na pedagogia da política. Petrópolis: Vozes, 1996.

VEIGA-NETO, Alfredo. Cultura e currículo. Contrapontos - ano 2 - n. 4 - Itajaí, jan/abr 2002.

WOODWARD, Katryn. Identidade e diferença: uma introdução teórica e conceitual. In: SILVA. Tomaz Tadeu (Org.). Identidade e diferença - a perspectiva dos Estudos Culturais. 15 ed. Petrópoles: Vozes, 2014.

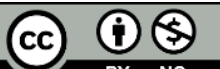

Este é um artigo de acesso aberto distribuído sob os termos da Licença Creative Commons Atribuição Não Comercial-Compartilha Igual (CC BYNC- 4.0), que permite uso, distribuição e reprodução para fins não comerciais, com a citação dos autores e da fonte original e sob a mesma licença. 